\title{
Design of Smart Packaging Machine Liquid Soap using Pugh's Method
}

\author{
Khairul Anwar Mohd Saib ${ }^{1}$, Muhammad Zahir Hassan ${ }^{2}$, Juffrizal Karjanto ${ }^{3}$, Nidzamuddin Md. Yusof ${ }^{4}$ \\ Norfariza Ab Wahab ${ }^{5}$ \\ ${ }^{1}$ Fakulti Teknologi Kejuruteraan Mekanikal dan Pembuatan, Universiti Teknikal Malaysia Melaka, Malaysia, \\ b071410544@student.utem.edu.my \\ ${ }^{2}$ Fakulti Teknologi Kejuruteraan Mekanikal dan Pembuatan, Universiti Teknikal Malaysia Melaka, Malaysia, \\ zahir@utem.edu.my \\ ${ }^{3}$ Fakulti Kejuruteraan Mekanikal, Universiti Teknikal Malaysia Melaka, Malaysia, \\ juffrizal@utem.edu.my \\ ${ }^{4}$ Fakulti Kejuruteraan Mekanikal, Universiti Teknikal Malaysia Melaka, Malaysia, \\ nidzamuddin@utem.edu.my \\ ${ }^{5}$ Fakulti Teknologi Kejuruteraan Mekanikal dan Pembuatan, Universiti Teknikal Malaysia Melaka, Malaysia, \\ norfariza@utem.edu.my
}

\begin{abstract}
Packaging is an important process for the laundry industry. The use of packaging machine technology in developing countries is to minimize production costs that will lead to a better economic development and packaging production. Current conditions in Malaysia, the heat impulse sealer is used for small industries to carry out the packaging business. A project was carried out to provide the design and development of packaging machine, either manually or mechanically. The objective of this project was to create a new concept of producing a packing containing a cleaning fluid using Pugh's Method. The machine was designed to reduce human effort to pack a cleaning fluid. In order to reduce human effort to operate the machine, a Manual Stamping Filling Sealing (MSFS) machine was designed based on several concept ideas, computer aided drawing software and CATIA V5 was used to design the MSFS machine. The target groups for this project are the household and industrial detergent companies.
\end{abstract}

Key words: Design, liquid detergent, packaging

\section{INTRODUCTION}

The packaging of liquid detergent in Malaysia is traditionally done by manual methods. Insertion or filling of liquid is done separately from the sealing process. An impulse sealer shown in Figure 1 is usually used in this sealing process. This machine is widely used in household, supermarket, shop and service industries for its convenience and easy in operation. The involved method is drudgery and consumes a longer time in production. In addition, the design of the impulse sealer has a drawback. It will be difficult to seal a package of liquid substance in horizontal position as it will spill out from the package.
The mechanical operation of heat impulse sealer is similar to a scissor where there is a pivot at one end of the design called hinge [1]. A plastic film package will be placed in the middle between the platen arm and the heating element for the sealing process. Other design improvements have been made for example in making a heat bag sealer which function is to seal together plastic to create an airtight closure. It is specially design to seal bags of orange juice [2]. Their proposed method is to seal bag without air by simply increase the filling of the bag a little higher than the level intended seal shown in Figure 2.

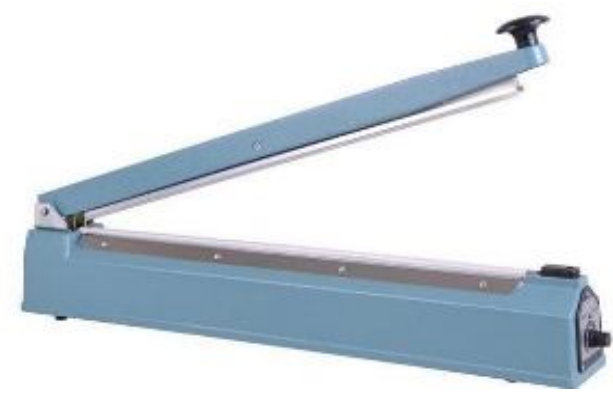

Figure 1: Example of a heat impulse sealer [1]

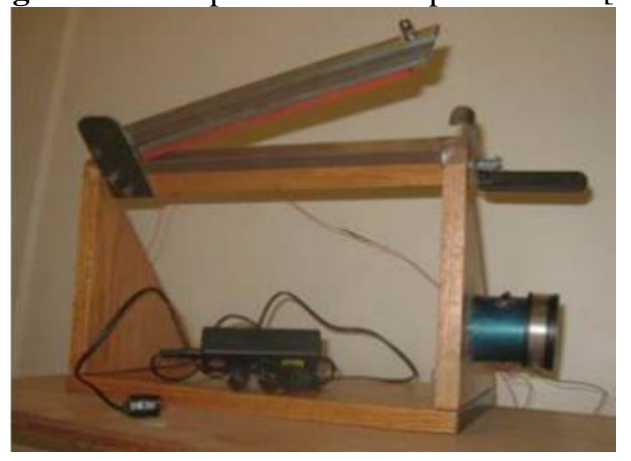

Figure 2: The Orange Juice Sealer [2] 
The proposed process for Manual Stamping Filling Sealing (MSFS) machine is design based on a study of background of functionality and performance for filling, forming, and sealing [2]. Filling is a process of pouring or inserting a medium, in a form of solid or liquid, into a container or a hole, for example, plastic package or bottle. This process is one of the important factors that needs to be considered in the development of MSFS machine. This filling process is an added feature in MSFS machine. The filling process is operated by a piston which is controlled by a pair of control valves. Typically, the liquid reservoir is placed on top of the container with the nozzle extending outwardly toward the container [3]. Forming process is an approach to make the film into a desired shape [4]. In this process, first, a tube is formed using a film or flexible thermoplastic packaging material. The film is drawn downward into forming collar to form a longitudinal edge. The longitudinal extending margins of the web overlap each other in a parallel position. The forming takes place around the filler tube. The longitudinal seam formed by the overlapping of film edge is pressed and heat is applied to seal the film [5]. Next, is the sealing process which involve the binding of two thermoplastics together using heat and pressure. This process usually takes place after the container or film has been filled.

The heat sealer and cut-off devices for the film material, such that the severing element, must move in a line that is longitudinal with the film to provide adequate contact time and completed the seal. The device is designed to produce a fin seals package [6]. The problem where the exposed portion of the sealing jaw and the lateral dimension of the film is not in good shape has been minimized. Thus, it improved the method by not covering the gripping or sealing with an insulating material [7]. These three combination of processes are needed to accomplish the MSFS machine.

\section{DESIGN CONCEPT}

There are many ideas were generated but not reported as it was in the early stage in designing process and therefore only several concepts were feasible to proceed to conceptual designs while the irrelevant ideas were eliminated [8]. The flow of the conceptual design started from morphological chart, concept scoring, concept screening, and lastly Pugh selection method. The Pugh's selection and assessment are evaluated by summation of ' + ' and ' - ' that indicates the element presented in the criteria. The ' + ' will be multiplied by weighing that been assessed for every criterion before been total up and the result is presented using Pugh method. Embodiment design is well known in product development. The main principles are minimum manufacturing costs, minimum requirements, minimum of weights, minimum losses and optimal handling [9]. There were six criteria of concern to be evaluated for the best selection of conceptual design as shown in Table 1.
Table 1: Pugh's selection used in this study

\begin{tabular}{|l|c|c|c|c|}
\hline Criteria & Weight & Design 1 & Design 2 & Design 3 \\
\hline Description & $(1-10)$ & Concept 5 & Concept 7 & Concept 8 \\
\hline $\begin{array}{l}\text { Easy to be } \\
\text { build }\end{array}$ & 5 & + & - & - \\
\hline Cost & 8 & + & + & - \\
\hline Lightweight & 7 & - & - & + \\
\hline $\begin{array}{l}\text { Low } \\
\text { maintenanc } \\
\text { e }\end{array}$ & 6 & + & - & + \\
\hline $\begin{array}{l}\text { Minimal } \\
\text { component }\end{array}$ & 4 & - & + & - \\
\hline $\begin{array}{l}\text { Easy to be } \\
\text { operated }\end{array}$ & 8 & + & - & - \\
\hline$\Sigma(+)$ & & 27 & 12 & 13 \\
\hline$\Sigma(-)$ & & 11 & 26 & 25 \\
\hline TOTAL & & 16 & -14 & -12 \\
\hline
\end{tabular}

Concept 5 was selected as shown in the Figure 3. The criterion are as follows:

- Easy to be build

- Cost

- Lightweight

- Low maintenance

- Minimal component

- Easy to be operated

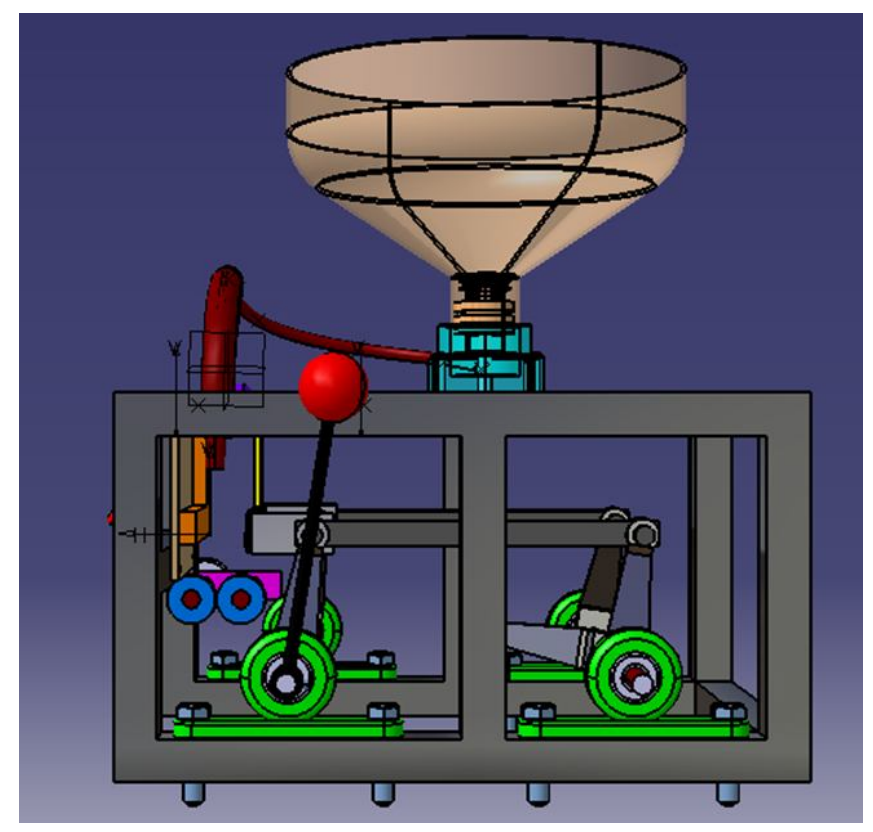

Figure 3: Selected Concept 5

\section{COMPONENT OF CONSTRUCTION}

The main components of the machine are; shaft, frame, roller, funnel, handle, cylinder head, diamond head, hollow shaft, sealing part assembly, roller assembly, and subcomponents like bearing, bolt, universal joint, bracket and was also selected. A three-dimensional (3D) construction is an essential part in earlier stage for design and production of a 
real working prototype [10], [11]. Hence, the product configuration and the architecture of the packaging was prepared using CATIA V5 software. Using 3-dimensional visualization (see Figure 3), the geometry and mechanism by which the components assembled together is clear and understandable. The working principle of this machine is human-force operated by means of transmitting motion from the handle to the 4-bar linkage of the driving mechanism and also the slider-crank mechanism. The stamper horizontally stamping operates back and forth motion which is converted from the rotational motion of handle shaft (drive). At the same time, the back shaft (driven) converting the rotational motion to the slider-crank mechanism in order to generate upward and downward motion of the cylinder head and diamond head in the funnel. Liquid detergent in the funnel is flowing into the fluid collector when the push rod moves upward and stop the liquid detergent to flow into the fluid collector when the push rod is moving downward. The physical decomposition is as shown in Figure 4.

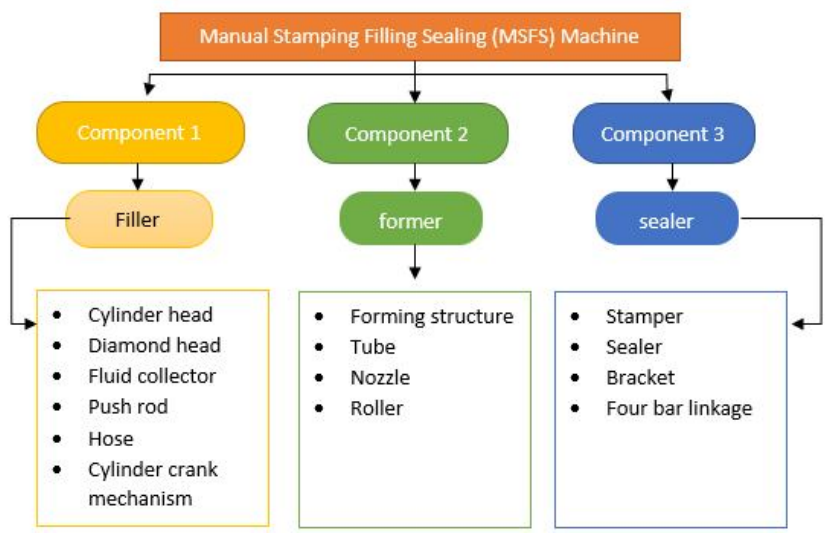

Figure 4: Physical decomposition

\section{WORKING PRINCIPLE}

This phase highlights the criteria of the functional analysis for the MSFS machine (see Figure 5). The process of combining three different processes which are filling, forming, and sealing is explained in details until the detergent pouch is produced as shown in Figure 6.

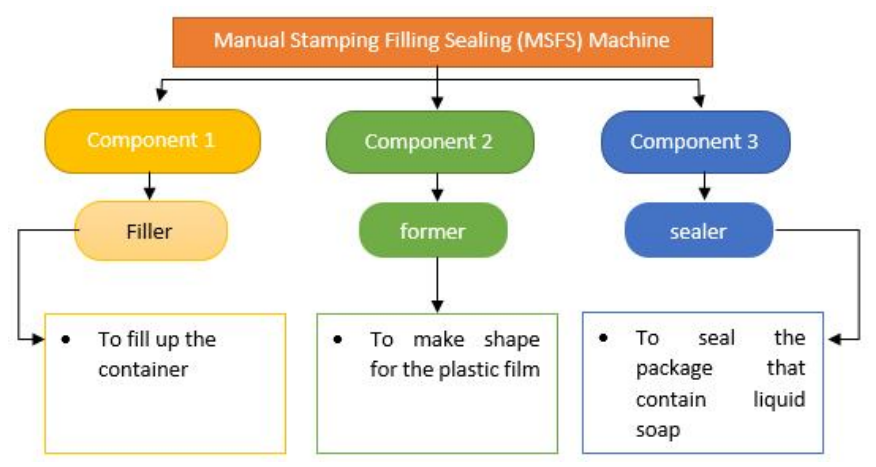

Figure 5: Functional analysis

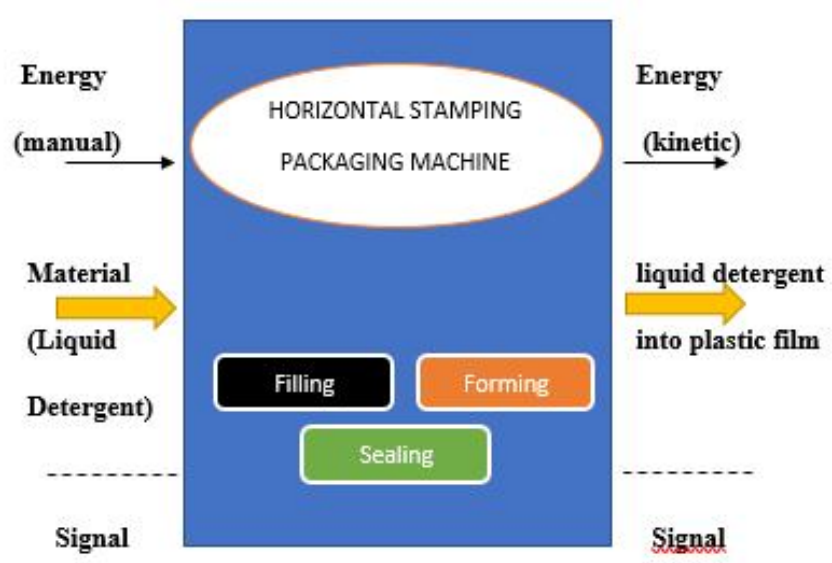

Figure 6: Input and output diagram

\subsection{Filling Station}

For the filling station, a piston and cylinder concept was chosen. The concept was generated based on the simplicity of the moving liquid. The concept of this design is referred to liquid filling as shown in Figure 7.

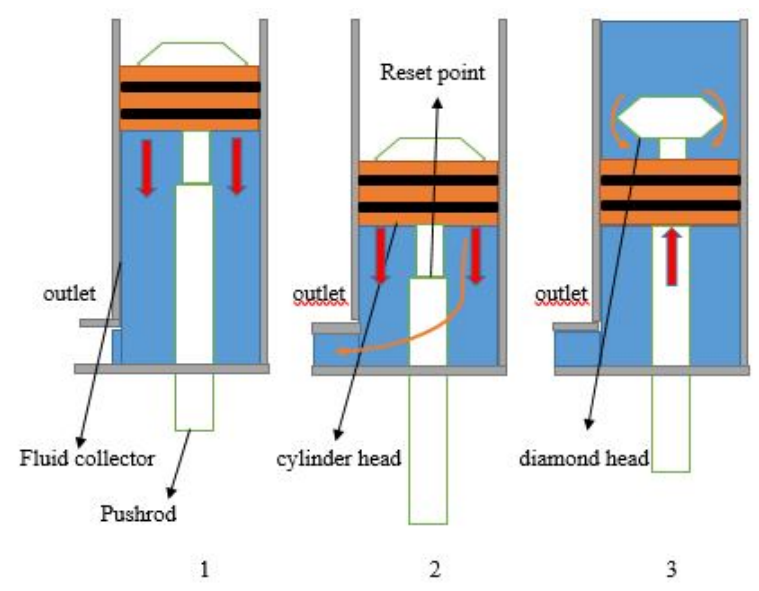

Figure 7: Filling process; Stage 1-2 is the compression position and Stage 3 is the reset position

\section{Stage 1-2: Compression position}

In this position, the push rod is moving downward. The fluid in the fluid collector is compressed downward by the cylinder head (Figure 8) and diamond head (Figure 9). The inlet hole of the cylinder head is closed by the diamond head which functions is to block the liquid detergent flow from the funnel to flow into the fluid collector. The liquid detergent is pumped into the outlet hole and flows out from the fluid collector. 


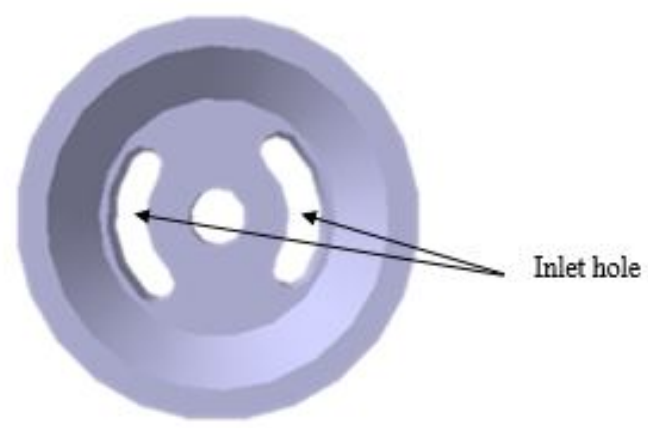

Figure 8: Cylinder head

\section{Stage 3: Reset position}

In this position, the push rod is moving upward as well as the diamond head because they are fixed together. Thus this action will open up a gap between the cylinder head and the diamond head. The cylinder head can move freely along the push rod but is limited by the presence of the reset point. The reset point pushes the cylinder head upward and increases the volume of the fluid collector allowing fluid to flow through the inlet hole of the cylinder head. As the push rod moving upward, the volume in the fluid collector will be increased. During this process, the fluid in the fluid collector is not flowing to the outlet hole because there is no difference in pressure at the fluid collector and funnel.

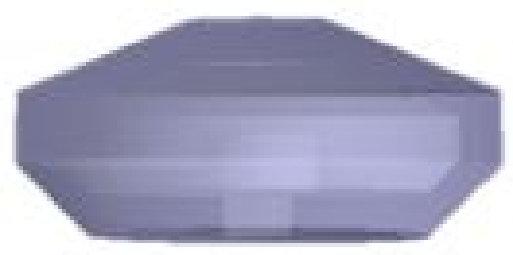

Figure 9: Diamond head

\subsection{Forming Station}

Figure 10 (a) shows the forming process of a plastic film. The film is slid on the U-shape of the forming structure (Figure 10 (b)) where the film has to be symmetrical on both sides on the forming structure. The film will move from horizontal position to vertical position (downward) as the roller rotates. The function of the roller is not only as the moving mechanism for the film, but also to provide a tension to the film, so that the film will not slip and it is always in symmetrical position. The roller is rotating manually by the user.

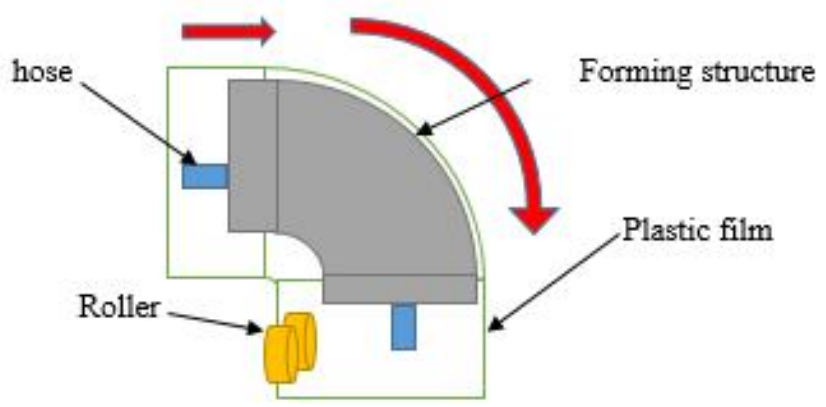

(a)

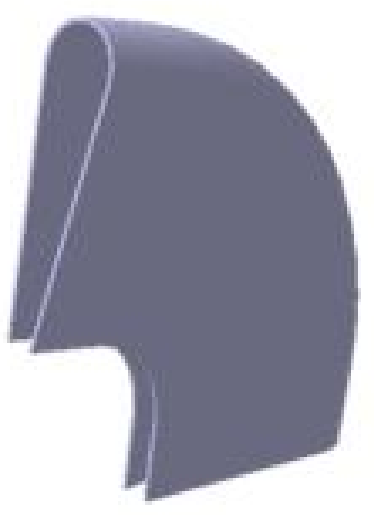

(b)

Figure 10: Forming Structure; (a) Forming process and (b) Design structure

\subsection{Sealing Station}

Figure 11 shows the sealing process of the plastic film. The film from the forming station will go through the sealing process. During this stage, the filling of liquid detergent and the sealing of the film occur simultaneously. The sealer is designed in an L-shape with the stamper as shown in Figure 11. The sealer is fixed with screws to the machine frame while the stamper is fixed with a bracket which was mechanically linked with the 4-bar-linkage mechanism as shown in Figure 12. As the handle moves forward, the stamper will also move forward in a horizontal direction. Figure 13 shows the stamping position during the sealing process. During the stamping process, the package film is already filled with a liquid detergent through the nozzle. The process is repeated. A 3-side seal package is produced as a result of this working operation (Figure 11). 


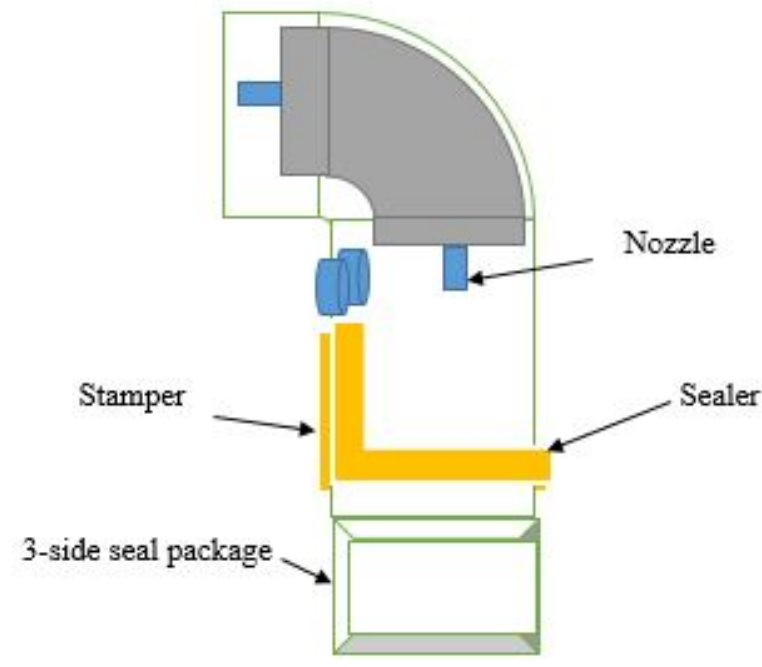

Figure 11: Sealing Process

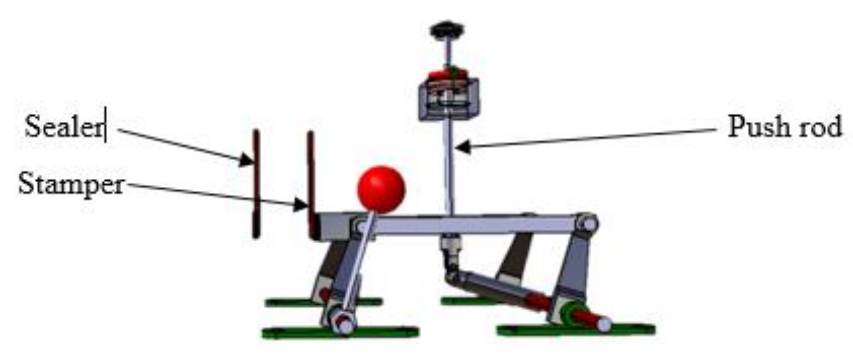

Figure 12: Filling Position

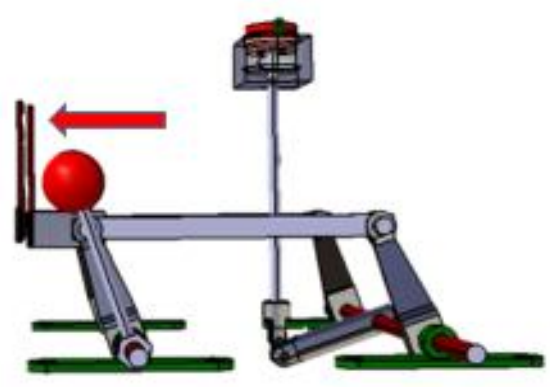

Figure 13: Stamping Position

\section{PRODUCT ANALYSIS}

\subsection{Frame Analysis}

By assuming that a total load of force of $70 \mathrm{~N}$ is applied at the top surface of the frame (Figure 14), a stress distribution of the elements on the frame is presented in a graphical mode of Von Mises Stress (Figure 14). The figure represents a torsional stress contours analysis with the maximum torsional stress of $5250 \mathrm{~N} / \mathrm{m}^{2}$ (reddish region), located at the intersection of the second pole and the two bar.

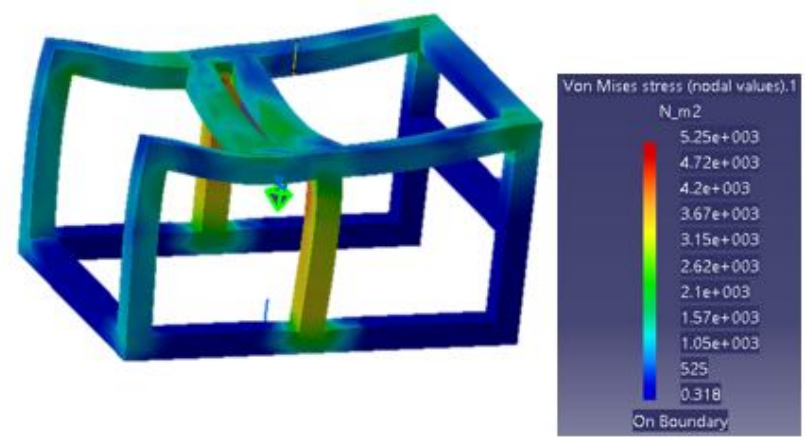

Figure 14: Frame Analysis - Von Mises Stress

\subsection{Clamp Analysis}

A $40 \mathrm{~N}$ of force is applied at the side surface of the clamp to check the stress distribution of the elements on the clamp by the representation Von Mises Stress in a graphical mode. Figure 15 shows the torsional stress contours analysis. The maximum torsional stress of $24 \mathrm{~N} / \mathrm{m}^{2}$ is displayed (reddish region) and was found located in the middle of the edges of the flat region of the clamp.
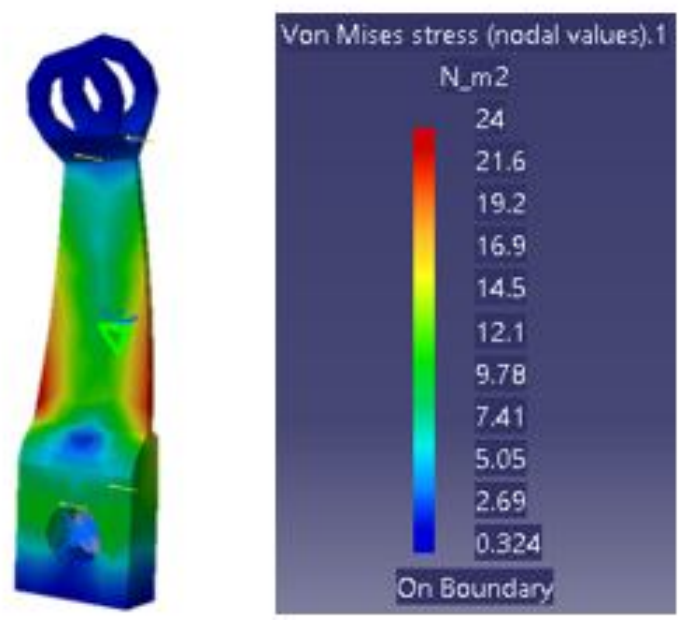

Figure 15: Clamp Analysis - Von Mises Stress

\subsection{Bracket Analysis}

A $40 \mathrm{~N}$ force is applied at the side surface of the bracket to check the stress distribution of the elements in the bracket by the representation Von Mises Stress in a graphical mode. Figure 16 shows the torsional stress contours analysis. The maximum torsional stress of $18600 \mathrm{~N} / \mathrm{m}^{2}$ is displayed (reddish region) and was found located only at the junction of the bracket. 


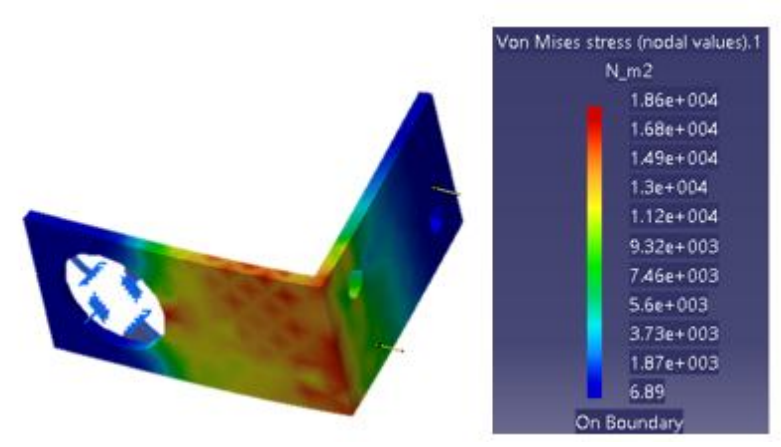

Figure 16: Bracket - Von Mises Stress

\section{CONCLUSION}

This paper presents the design of manually operated packaging machine called Manual Stamping Filling Sealing (MSFS) machine. The MSFS machine features three processes in a machine; filling, forming and sealing. It is designed to be operated by single person. Even though it is not currently used commercially in industries as well as in a small enterprise industry, the design presented here could be produced in local industries. The MSFS machine can be operated with an affordable capacity. That, in turn, able to provide the household to use the machine in affordable cost and generate income in packaging detergent industries.

\section{ACKNOWLEDGMENT}

The authors would like to thank the support and guidance given by Faculty of Mechanical and Manufacturing Engineering Technology (FTKMP) and the Center for Research and Innovation Management (CRIM) Universiti Teknikal Malaysia Melaka (UTeM) for publication sponsorship of the present article.

\section{REFERENCES}

[1] Yescomusa, 20" Plastic Bag Sealer Impulse Heat Sealing Machine, [online] yescomusa.com available at: https://www.yescomusa.com/products/20-plastic-bag-se aler-impulse-heat-sealing-machine.

[2] Chang, C., Conrad, B., Leonard, B. and Rosser, E., The orange juice sealer, MIT D-Lab, 2011.

[3] Zimmermann, G., Liquid Filling Machine, U.S. Pat. 4282698, 1981.

[4] Mosher, O. A., Packaging Machine with Variable Sealing Jaw Displacement Apparatus, U.S. Pat. 4768327, 1988.

[5] Kelly, R. C., Method and Apparatus for Automatically Filling Bag with Particulate Materials, U.S. Pat. 4090344, 1978.

[6] Ramsey, H. E. and Fisher, E. E., Heat Sealing Film Cut-Off Device, U.S. Pat. 4433527, 1984.

[7] Leimert, J., Apparatus for Sealing Film, U.S. Pat. 3530642, 1970.

[8] Pahl G., Engineering Design; A Systematic Approach, Germany, 3rd Ed. 2007.

[9] Kesselring F., Technical Composition, Springer, Berlin, 1954.

[10] Hillary V. and Alexi D., Pet Food Dispenser Design Using Raspberry $\mathbf{P i}$, International Journal of Emerging Trends in Engineering Research (IJETER), Vol. 8, $\quad$ No. 4, pp. 1251-1254, 2020.

[11] Farhana M., Hassan M., ZubaidiFaisel M. R., Timothy Yuen W. H. and Muhammad S. K., Design and Prototyping of a Motorized Legged Robot with Klann Linkage Mechanism, International Journal of Emerging Trends in Engineering Research (IJETER), Vol. 8, No. 5, pp. 1941-1945, 2020. 